\title{
PROCEDURAL FAIRNESS AND INCENTIVE PROGRAMS: REFLECTIONS ON THE ENVIRONMENTAL CHOICE PROGRAM
}

\section{DAVID COHEN*}

This paper explores the application of concepts of procedural fairness to the federal government's Environmental Choice Program's decision-making processes. While Canadian courts have traditionally required public bureaucrats to act "fairly" when implementing command models of regulation, they have only recently been confronted with demands that regulators implementing economic incentive programs also act in accordance with procedural fairness norms.

Procedural fairness has been justified through a number of related arguments, all of which focus on the protection of private interests of individuals adversely affected by the exercise of bureaucratic power. The paper argues that procedural fairness should characterize both decision-making categories within the Environmental Choice Program, and within incentive programs generally. However, the paper argues that the justification for the application of fairmess norms in government incentive programs should be the promotion and support of program policies. At best, the protection of private interests is the means through which program benefits can be optimally designed, and effectively delivered to the public.

The paper describes the Environmental Choice Program's decision-making processes, and divides the program 's operations into two categories. CATEGORY I decisions involve the development of environmental standards, and the negotiation of the licensing agreement through which private firms are permitted to use the federal government owned ECOLOGO. CATEGORY 2 decisions involve individual licensing, licence termination and renewal decisions. The paper then discusses the ways in which effective participation of a wide range of interest groups is encouraged in both categories of decisions through access to information. representation on decision-making bodies, and appeal and review processes. Finally, the paper describes the environmental benefits associated with effective participation as an example of the public policy objectives of fairness doctrines.

\section{TABLE OF CONTENTS}

I. INTRODUCTION $\ldots \ldots \ldots \ldots \ldots \ldots \ldots \ldots \ldots \ldots \ldots$

II. THE CONVERGENCE OF MARKETS

AND PUBLIC POLICY $\ldots \ldots \ldots \ldots \ldots \ldots \ldots \ldots \ldots$

III. THE ENVIRONMENTAL CHOICE PROGRAM . . . . . . . . . 556

IV. A CASE STUDY PROCEDURAL FAIRNESS

AND THE ENVIRONMENTAL CHOICE PROGRAM . . . . . 557

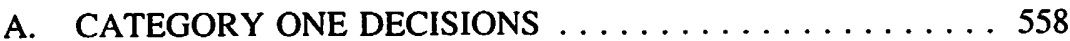

B. CATEGORY TWO DECISIONS ............. 563

V. THE PROGRAMMATIC BENEFITS OF

PROCEDURAL FAIRNESS $\ldots \ldots \ldots \ldots \ldots \ldots 6$

A. ACHIEVING STRATEGIC

PROGRAM OBJECTIVES . . . . . . . . . . . . 566

Associate Professor, Faculty of Law, University of British Columbia. The author is a member of the Environmental Choice Board, and the Executive Subcommittee of the Board. All of the views expressed in this paper are those of the author only, and do not necessarily reflect the policy of Environment Canada, or of the Environmental Choice Program. The description of the Environmental Choice Program's decision-making process is accurate as of July 1991. There have been numerous and substantial changes to the decision-making process since 1991. Interested parties can contact the author for current information. 
B. IMPROVING BUREAUCRATIC ACCESS

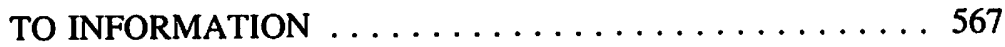

C. IMPROVING GUIDELINE DRAFTING $\ldots \ldots \ldots \ldots \ldots 568$

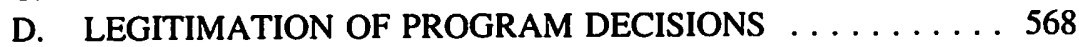

E. REDUCING ENFORCEMENT COSTS ........... 569

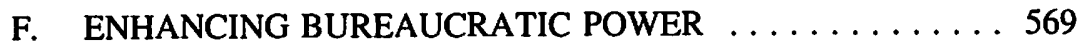

VI. CONSTRAINTS ON FAIRNESS $\ldots \ldots \ldots \ldots \ldots \ldots \ldots \ldots . \ldots \ldots 1$

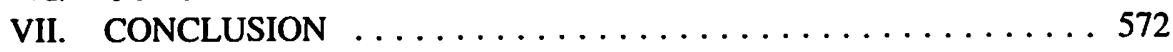

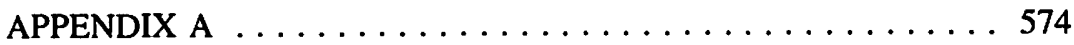

\section{INTRODUCTION}

Government regulation of human activity affecting the environment, ${ }^{1}$ may take an infinite variety of forms ranging from direct state ownership of the means of production to implicit state support of private ownership and exchange relations through private law. Like that of most Western nations, Canadian environmental policy has traditionally chosen a position well within these extremes ... employing simple "on/off" penal commands regulating the production of atmospheric, land and water effluents. More recently, regulatory policy has involved increased state expropriation of private property for public conservation purposes, and more sophisticated incremental (albeit command) models of regulation which link a range of penalties to increasingly harmful activities.

Not unexpectedly, the monitoring costs of command models of regulation, whether focusing on effluent regulation, or on the existence of some deleterious impact on environmental quality have proven to be substantial. As well, regulators have faced significant political and economic costs when forced, by the regulatory model they have chosen, to initiate Draconian enforcement powers including plant closures and production stoppages. As a result, environmental policy analysts have mandated performance and design production processes through a complicated system of permits and licences, and have developed a number of economic instruments including direct and indirect tax subsidies for investment in pollution control technology, and tradeable pollution rights to influence activity which affects the environment. ${ }^{2}$

1 The broadest definition of the environment which might be employed in discussing environmental policy is "the aggregation of material (physical and biological) resources, and the processes through which they are transformed." The definition which I employ is considerably narrower. It accepts, for the purposes of current government environmental policy, a homocentric environmental ethic. The definition of the environment employed in this paper is the "collection of physical and biological resources currently available, whether transformed or capable of transformation, for human welfare." The one "process" through which those resources are transformed which I focus on in this paper is the market - the institution through which resources are created, transformed and distributed. It is unnecessary, for our purposes, to define the ways in which human welfare might be improved through the enjoyment of the resources, or their transformation.

This program is one, and perhaps the first, Canadian initiative which attempts to operationalize the concept of "sustainable development" articulated in the United Nations World Commission on Environment and Development published in 1987. The "Brundtland Report" entitled Our Common Future has been the subject of some legitimate skeptical criticism focusing on our ability to link economic and environmental choices, and on the assumption that development, rather than the environment should be our policy objective. As well, one can imagine a number of ambiguous ideas 
Public bureaucrats, whatever their chosen regulatory instrument, cannot, however, operate in pristine isolation from other social institutions. In particular, regulators must live out their lives within a legal environment over which they have little direct, shortterm influence. In Canada, as in many liberal democracies, legislators and regulators have had to tailor "command" models of regulatory policy and implementation to a range of constraints established by the judiciary. In particular, regulators have been directed by courts to act "fairly" in their exercise of state power over private interests. The deployment of more sophisticated regulatory weapons has generated judicial action designed in large part to continue this historical relationship with regulators. ${ }^{3}$

In this paper I address the prescriptive $e^{4}$ question which confronts bureaucrats designing fiscal incentive programs and other non-command models of environmental regulation:

\section{How should the procedural context within which the government operates be defined, when it rejects its more coercive regulatory weapons in favour of more effective, but apparently less coercive, regulatory instruments?}

Most legal analyses of "due process", procedural faimess, natural justice and related concepts adopt a variant of either a rights based or a "justice as process" argument in order to justify the application of procedural faimess norms to the regulatory process. All of these positions have in common an implicit "anti-bureaucratic" bias - procedural fairness represents the deployment of judicial forces to control bureaucratic power, not through definitions of statutory or constitutional authority or through the substitution of judicial for bureaucratic judgment, but through the development of allegedly neutral "fair" processes. $^{5}$

contained in the use of "sustainability". It can refer to the sustained yield of natural resources; it can refer to the sustaining of biodiversity in the environment; or it might refer to the sustaining of a specific rate of development. See, for example, "Brundtland message lacks economic base" The (Toronto/ Globe and Mail (14 June 1989) B2. See "Form and Function" Wall Street Journal (21 August 1990) B1.

3 I discuss these developments in detail in Part IV, below.

$4 \quad$ I admit that the descriptive companion to my question is extremely important to regulators. Within the first year of its operations the Environmental Choice Board faced a serious legal challenge to a decision to recommend a recycled paper product guideline. One of the grounds of the challenge was that the Board had not employed procedures which permitted affected parties the opportunity to participate effectively in the program. The very last thing which the Board, departmental bureaucrats, and the Minister of the Environment needed was a lawsuit, ultimately successful or not. The lawsuit is politically embarrassing, redirects valuable program resources, and signals other affected parties of one more potential delaying strategy. As one bureaucrat explained:

The Minister has extremely limited resources. Accordingly, he has two boxes on his desk - one containing "New Initiatives", the other "Problems". As we both know, the ECP is no longer a New Initiative.

$5 \quad$ The most technical simply ask whether the bureaucratic decision appears similar to those traditionally made by judges. Thus paradigmatic highly focused fact-finding, and the application of predetermined rules to those specific facts have been viewed as appropriate for the application of processes utilized by courts. Related analyses focus on the kind of order or rule which the bureaucrat is making. If the kind of remedial authority and its focus is close to that which courts would traditionally exercise, court-like processes are demanded. A slightly more interesting analysis has enquired into the kind of private interest (wealth, personal liberty, and the like), which is being affected by the exercise of 
Slightly different arguments focus on the implicit normative considerations which appear to influence judicial reasoning. ${ }^{6}$ More "principled" arguments posit that human beings (and corporations?) should be treated with respect and dignity. Individuals affected by bureaucratic choices should not be conceived as "means" to some greater utilitarian end; and even if they are, they are also individuals whose welfare counts.?

The most recent Canadian development in this area has been the articulation of what is known as the "reasonable expectation" doctrine. ${ }^{8}$ Although the doctrine has generated considerable academic debate, it is at best a modest expansion of the list of interests employed in traditional "rights" based analyses beyond those recognized by courts in common law adjudication. ${ }^{9}$ In theory, legitimate expectation analysis is applicable to the Environmental Choice Program in virtually all of its decision-making processes. ${ }^{10}$

bureaucratic power. The higher that interest ranks in the writer's list of human interests, the more likely that process rights will be recommended. See, for example, Kane v. Board of Governors of the University of British Columbia, [1980] I S.C.R. 1105 (high standard of justice required when right to continue employment is at stake).

For example, as legitimate power over labour relations was shifted from the courts to administrative agencies, with a concomitant shift in attitudes towards labour, one found, not surprisingly, that the courts continued to insist upon procedural protection in the administrative process for the corporate interests which could no longer be directly furthered in the judicial process.

Similarly, some have argued that notions of property as a concept which empowers individuals in their relationships with each other and the community means, in the modern welfare state, that receipt of government largesse ought to be afforded at least some of the traditional protection enjoyed by property right holders.

8 See Old St Boniface Resident's Association Inc. v. Winnipeg, [1990] 3 S.C.R. 1170, Reference Re Canada Assistance Plan. [1991] 2 S.C.R. 525 (legitimate expectations doctrine does not apply to decisions to introduce legislation in Parliament). See also Schmidt v. Secretary of State for Home Affairs, [1969] 1 All E.R. 904 at 909. Commonwealth developments in the area are canvassed in R.E. Riggs, "Legitimate Expectations and Procedural Fairness in English Law" (1988) 36 Amer. J. of Comp. Law 400.

See $\mathrm{Ng}$ v. Attorney General of Hong Kong, [1984] 2 All E.R. 346 per Lord Fraser at 350 who criticized the view of Barwick J. in Salemi v. MacKellar (No. 2) (1977), 137 C.L.R. 396; and Jim Harris Ltd. v. Minister of Energy (1980), 2 N.Z.L.R. 294 at 296 (benefit or privilege imports the concept of legitimate expectations).

One of the first legal opinions on procedural fairness received by the Board reflected this kind of formal analysis. The writer simply said that the program was distributing a "privilege" to, rather than affecting a "right" of the affected firm, and thus was under no obligation to provide firms with the opportunity to participate in decisions affecting their welfare. The problem with the analysis is that whether some benefit "is" a right depends on whether we decide to link it to procedural safeguards. In other words, if a court says that the program requires procedural fairness, then by definition, the program benefits are "rights", albeit protected only by procedural due process. If a court says that the program does not require procedural fairness, then, again by definition, the program benefits are not "rights".

These processes are described in detail in Part III. Briefly, they include:

the choice of tentative product categories;

the development of the substantive environmental criteria in specific environmental guidelines;

- the development of the terms of the contract through which the right to use the logo is regulated;

the consideration of applications for licenses;

the original decision to contract with a specific private sector company;

the issuance of a licence to use the ECOLOGO; and 
My thesis shares little in common with any of these traditional analyses. All of the "rights" based justifications of judicial review justify procedural protection on individualistic human rights grounds, or on utilitarian grounds which focus on the production and aggregation of wealth by "private" actors. While my thesis is highly utilitarian, I argue that procedural faimess in government incentive programs is required to further public policy objectives." That is, environmental policy objectives will be furthered, and incentive programs will operate more effectively if they incorporate substantial elements of procedural fairness. These programs should therefore provide considerable opportunities for meaningful and effective participation in their associated decision-making processes. ${ }^{12}$

In this paper, I develop that thesis with specific reference to the evolving structure and operations of the Environmental Choice Program. The Environmental Choice Program, which has been operating for some two years, involves the development of a federal government owned ECOLOGO, the establishment of product specific environmental guidelines, and the licensing of private manufacturers, distributors and retailers to use the logo on products which comply with the guidelines. However, the theory on which the thesis is based, suggests that it is applicable to a broad range of government incentive programs.

The development of procedural fairness in the Environmental Choice and related incentive programs recognizes the limitations on the resources available to public bureaucracies, the fallibility of bureaucratic decision-making, and the political reality within which public bureaucrats must operate. All of these are magnified when the state attempts to use the market to pursue public policy objectives.

\section{THE CONVERGENCE OF MARKETS AND PUBLIC POLICY}

The primary public policy objective of the Program is the improvement, or the reduction in the rate of deterioration of the environment, through the substitution in consumer markets, of "ECOLOGOED" products and services for products and services currently distributed in those markets. ${ }^{13}$ Products receive the ECOLOGO only if they comply with environmental standards, and thus the primary program objective

the decision to renew or terminate a licence, or to renew a licence on other than its prior terms.

"I am certain that many of the rights-based theorists will support the policy prescription which I offer. Like the some of the rights-based theorists, I acknowledge the risks of concentrated power whether in private or public bureaucracies. Effective participation may decentralize power across political actors, economic sectors, geographical areas, and special interest groups.

12 This is consistent with the language employed by several judges in explaining their decisions relating to "procedural fairness" and legitimate expectations. See R. v. Liverpool Corporation, [1972] 2 All E.R. 589 at 596 (procedural fairness will assist council to perform its statutory duties).

13. Subsidiary program objectives, and in part the operational means through which the primary objective will be achieved, include addressing consumer confusion relating to private initiatives involving environmental labelling, offering incentives to the private sector for investments in research and development in environmentally sensitive consumer products and services, and educating consumers about the complex links between "private" purchase decisions and the public environmental good. 
improving environmental quality through product substitution -- depends on the development of environmental standards which, if implemented, generate net environmental benefits.

This primary policy objective of the Environmental Choice Program the reduction in the total load on the environment as a result of the production, consumption and disposal of consumer goods - will be achieved through the substitution of ECOLOGOED products for existing products. However, as the following analysis indicates, achieving that policy objective is extremely difficult, and requires that the Program has relatively precise information regarding the relationship between two variables: the environmental benefits produced through the substitution of each unit of ECOLOGOED product, and the total number of ECOLOGOED units which will be sold as a result of the program. The way in which environmental and market parameters interact to optimize the delivery of program benefits is illustrated below. The analysis makes clear that bureaucrats require relatively precise information regarding the environmental loads of existing and potential ECOLOGOED products, and the nature of the relationship between the per unit environmental benefit and total sales of the replacement products under the Program.

Let:

$\mathrm{EC}=$ the environmental load of one unit of a non-ecologoed product in a particular category, and which is subject to replacement by an ecologoed product.

$\mathrm{EQ}=$ the environmental load of any one unit of an substituted ECOLOGO product in a particular category.

$\mathrm{U}_{\mathrm{o}}=$ the total unit sales of non-ecologoed products in a particular category.

$\mathrm{U}_{\mathrm{r}}=$ the total unit sales of ECOLOGOED products within a particular category.

$L_{0}=$ the environmental load associated with the total production, consumption and disposal of all non-ecologoed products in a particular product category.

$\mathrm{L}_{\mathrm{n}}=$ the environmental load associated with the total production, consumption and disposal of all non-ecologoed products and replacement products in a particular category.

$R_{c}=$ the ratio of the environmental load of one replacement unit to an existing unit.

$R_{u}=$ the ratio of unit sales of replacement units to unit sales of existing units. 


\section{THEN:}

$$
\begin{aligned}
\mathrm{L}_{\mathrm{o}} & =\mathrm{ECUo} \\
\mathrm{L}_{\mathrm{n}} & =\mathrm{EC}\left(\mathrm{U}_{\mathrm{o}}-\mathrm{U}_{\mathrm{r}}\right)+\mathrm{EQU}_{\mathrm{r}} \\
& =\mathrm{ECU}_{\mathrm{o}}-\mathrm{ECU}_{\mathrm{r}}+\mathrm{EQU}_{\mathrm{r}}
\end{aligned}
$$

AND:

$$
\begin{array}{lll}
\mathrm{R}_{\mathrm{c}}= & \frac{\mathrm{EQ}}{\mathrm{EC}} & \text { RANGE }=0 \text { to } 1.0 \\
\mathrm{R}_{\mathrm{u}}= & \underline{\mathrm{U}}_{\mathrm{U}} & \mathrm{RANGE}=0 \text { to } 1.0
\end{array}
$$

One can predict, as EQ approaches 0 , and thus as $R_{c}$ approaches 0 , that units sales of replacement products will also approach 0 . And when $U_{r}=0$, then

$$
\mathbf{R}_{\mathrm{u}}=\frac{\mathrm{U}_{\mathrm{U}}}{\mathrm{U}_{\mathrm{o}}} \quad=0
$$

Similarly, if EQ (the environmental load of one unit of a replacement product) is not reduced at all, then $R_{c}=1$, and the replacement product will be a perfect substitute for the existing product. One can assume for the purposes of this analysis that all consumers then make the substitution, given that they desire the environmental quality which is apparently being supplied, and every other aspect of product performance is kept constant. In this case, $\mathrm{U}_{\mathrm{r}}=\mathrm{U}_{\mathrm{o}}$, and

$$
\mathbf{R}_{\mathrm{u}}=\frac{\mathrm{U}_{\mathrm{U}}}{\mathrm{U}_{\mathrm{o}}} \quad=1
$$

That is, in the worst case environmental scenario, $R_{c}$ will approach 0 , but $R_{y}$ will also approach 0 . Similarly, in the best case environmental scenario, we can assume that as $R_{e}$ approaches 1 , that $R_{u}$ will also approach $1 .^{14}$

By looking at Figure 1 one can better understand the nature of the problem confronting the program. Knowledge about the way in which $R_{u}$ and $R_{c}$ vary with one another is critical to the success of the program. All one knows, with any degree of certainty, is the two endpoints, and it is the shape of the curve which counts! All of the program decisions relate to the development of guidelines which generate $E Q$, and thus $R_{e}$. And one can predict $R_{e}$ only if one can accurately calculate EC and EQ. However, even perfect

14 If perfect substitution does not take place, then the shape of the curves becomes even more problematical, as we no longer know where the top right point is located! The assumption, while necessary to draw the curves, may be misleadingly optimistic. 
information about EC and EQ, will, by itself produce no information about the function in any intermediate position.

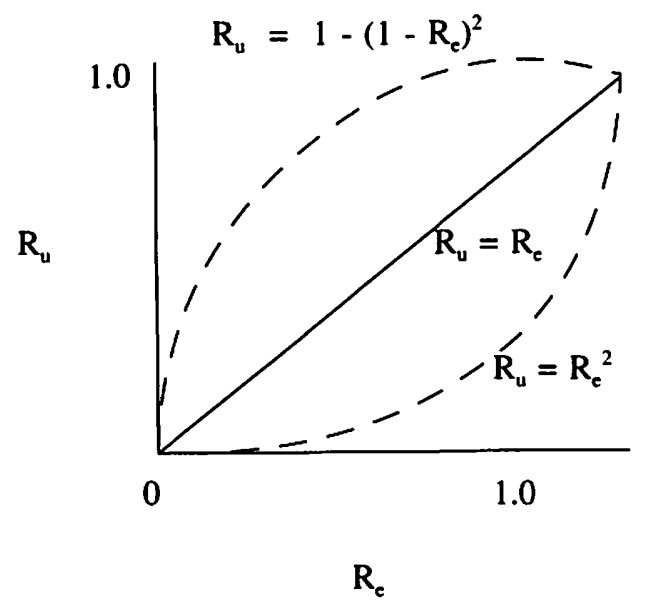

Figure 1

In order to minimize $L_{n}$ through the development of environmental guidelines, one needs to know the way in which $R_{u}$ varies with $R_{c}-$ that is, one needs to know the shape of the curve.

The next stage in the analysis, which is illustrated in Figure 2, recognizes that in order to maximize program benefits by minimizing $L_{n}$, we must be able to calculate the unique $\left(R_{e} R_{u}\right)$ function for each product category. It is obvious that if $R_{c}$ equals 1 , then $L_{n}$ will equal $L_{0}$, since, although all replacement products will be sold, there will be no environmental benefit produced by the substitution. Similarly, if $R_{c}$ equals 0 , then $L_{n}$ will again equal $L_{o}$, since there will be no replacement products sold. Minimizing $L_{n}$, by producing a specific EQ for a product category, requires that we know the $\left(R_{e} R_{v}\right)$ function for the particular product category for which the environmental guideline is being developed. That is, the new load $\left(L_{n}\right)$ is expressible in terms of the old load $\left(L_{o}\right)$ and the two ratios.

$$
\begin{aligned}
\mathrm{L}_{\mathrm{n}} & =\mathrm{ECU}_{\mathrm{o}}-\mathrm{ECU}_{\mathrm{r}}+\mathrm{EQU}_{\mathrm{r}} \\
\mathrm{EQ} & =\mathrm{R}_{\mathrm{c}} \mathrm{EC} \\
\mathrm{U}_{\mathrm{r}} & =\mathrm{R}_{\mathrm{u}} \mathrm{U}_{\mathrm{o}} \\
\mathrm{L}_{\mathrm{n}} & =\mathrm{ECU}_{\mathrm{o}}-\mathrm{ECR}_{\mathrm{u}} \mathrm{U}_{\mathrm{o}}+\mathrm{R}_{\mathrm{c}} \mathrm{ECU_{r }} \\
& =\mathrm{ECU}_{\mathrm{o}}\left(1-\mathrm{R}_{\mathrm{u}}+\mathrm{R}_{\mathrm{c}} \mathrm{R}_{\mathrm{u}}\right) \\
& =\mathrm{L}_{\mathrm{o}}\left(1-\mathrm{R}_{\mathrm{u}}+\mathrm{R}_{\mathrm{c}} \mathrm{R}_{\mathrm{u}}\right)
\end{aligned}
$$


Figure 2 demonstrates the relationship between $L_{n}$ and EQ for three hypothetical $R_{c} R_{u}$ functions. ${ }^{15}$

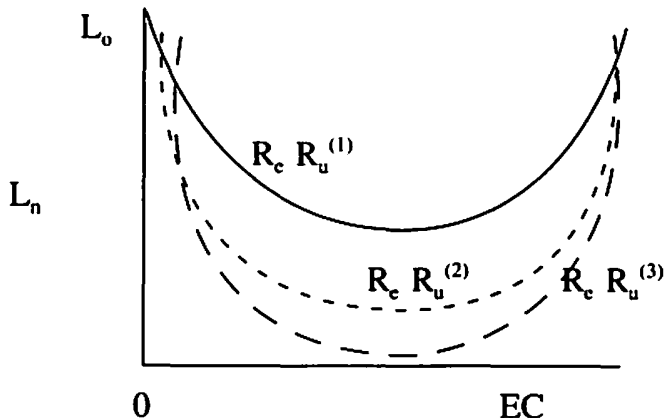

EQ

Figure 2

To reiterate, the primary objective of the Environmental Choice Program is to reduce the total environmental load generated by the production, consumption and disposal of consumer products - that is, to minimize $L_{n}$ in each product category. However, knowing whether $L_{n}$ is being reduced, as well as knowing the magnitude of that reduction, requires that one identify and measure EC and $\mathrm{U}_{\mathrm{v}}$ with some degree of accuracy. It is clear that the environmental load of existing products (EC) is extremely difficult to identify and quantify. EC is currently unknown for virtually all existing products. Even if EC could be calculated for a product produced by a particular manufacturer, one must be able to predict from which particular products demand will shift once consumers are given the opportunity to choose ECOLGOED products. It is obvious, given a number of producers and a range of product designs and manufacturing processes, that EC will not be constant across all units within $U_{0}$. Thus the calculation of EC requires not only an environmental impact analysis which generates EC for all existing products within a product category, but also a market analysis of the shift in demand which will be generated by the deployment of the ECOLOGO. It may be that those consumers who do purchase logoed products are already buying products with low environmental loads, meaning that the marginal per unit gains might be quite small.

In addition, knowing whether $L_{n}$ is being reduced, and knowing the magnitude of that reduction, requires that $E Q$ and $U_{r}$ be measured with some degree of accuracy. As with the calculation of EC, the task of estimating the environmental load of ECOLOGOED products is extremely difficult - in fact, more difficult than estimating EC, given that in

15. The importance of knowing the unique $R_{e} R_{v}$ function for each product category is illustrated in Appendix A. 
this case the new product may not be in production. ${ }^{16}$ Similarly, calculating $\mathrm{U}_{\mathrm{r}}$ requires accurate information about a range of variables including the number and identities of the subset of all producers who will be able to comply with the environmental standards and who will apply for the ECOLOGO, and the nature and degree of the shift in consumer demand for the new product.

Most importantly, setting environmental guidelines which reduce $L_{n}$, must take into account the relationship between EQ and $\mathrm{U}_{\mathrm{r}}$ that is, as EQ is reduced towards $0, \mathrm{U}_{\mathrm{r}}$ will also likely be reduced towards $0 .{ }^{17}$ As the environmental guidelines reduce the environmental load associated with any one unit of an ECOLOGOED product, the total number of units sold will fall. The result, unfortunately, is that optimizing program output means developing environmental guidelines which do not necessarily reduce $\mathrm{EQ}$ to 0 , but rather reduce EQ, taking into account the reduction in $U_{r}$, such that $L_{n}$ is minimized.

Data necessary to calculate EC and EQ, as well as $U_{o}$ and $U_{r}$, requires not only scientific environmental impact analyses, but also projected market analyses taking into account pricing decisions and demand for substitutable consumer products, manufacturing processes, sources of raw material, access to capital, the timing and feasibility of plant modifications, and so on. There is little reason to believe that public bureaucracies have the information upon which to base these market analyses, or have a great deal of experience in making these kinds of business decisions. Participation by environmental groups, independent scientists and the relevant industry will contribute significantly to the program's ability to ascertain these variables. Effective participation in program decisionmaking will assist in predicting the way in which EQ and $U_{r}$ relate to one another across a particular industry, given the distribution of capital, technology, access to raw materials, plant equipment and location, elasticity of demand for particular products, consumer demand for environmental "quality" in consumer goods, and so on, within that industry. Procedural fairness which permits public bureaucrats access to the private sector in a structured and strategic way, is the only way to generate information which defines the complex relationships between these variables.

The economic rationale of the program acknowledges that market failures may occur; but the program addresses market failure with market mechanisms rather than through traditional command models of government regulation. Environmental degradation represents a negative externality generated by private market transactions. The

Precise quantification of EQ is almost impossible. First, estimating EQ is extremely difficult given the absence of a developed methodology for environmental impact analysis of many products or services. Second, the methodology, even if defensible, must be applied to proposed products and services, producing extremely uncertain predictions. Finally, actual (as opposed to expected) EQ will depend on the degree of individual manufacturer compliance with the environmental standards at given levels and strategies of monitoring and enforcement by the program.

17 That is, as environmental standards are made more rigorous, total sales may decrease due to increased production costs and thus prices, and to a reduction in the number of suppliers who can produce goods which comply with the standards given existing distributions of raw materials, technology, and geographical and market product shares. What the program attempts to do is to develop environmental guidelines which optimize the generation of environmental benefits, given these two inversely related variables. 
[VOL. XXXI, No. 3 1993]

Environmental Choice Program is based on the idea that improvements in environmental quality represent a positive externality which might similarly be generated through private market transactions.

To date, environmental benefits are likely being underproduced for several reasons. First, consumers may not enjoy a credible signal describing the environmental characteristics of consumer goods which they can employ in making purchase decisions. Second, producers of the environmental improvement, given its public good character, may under-invest in its production, since many more persons than the purchaser will enjoy the environmental benefits without having to, or being able to reflect their choices in the market. Third, some producers of "environmental improvement" may not be able to recoup their production costs where consumers are skeptical of private claims of environmental responsibility. The state, through an investment of public resources in creating a credible ECOLOGO, and through the distribution of the right to use the ECOLOGO, simultaneously addresses the information imperfections which now characterize this market, ${ }^{18}$ and rewards firms which engage in conduct which produces the environmental good. ${ }^{19}$

However, the foregoing analysis of the way in which regulatory policy and markets in consumer products interact confirms that it is unlikely that incentive programs, like the Environmental Choice Program, could be expected to work perfectly. Procedural fairness is a regulatory response which recognizes that regulatory models, while necessary to the program design process, are never perfectly replicated in practice. What one can predict is that the Environmental Choice Program, like many government incentive programs, may be subject to what may be called second order market failure which prevents it from achieving optimal public benefits.

The Environmental Choice Program assumes that environmental degradation is due, at least in part, to market failure in the production of consumer goods and services. The

18 One problem which has not yet been addressed adequately is the intractable problem of quantifying the "public good" represented by a reduction in the rate of environmental degradation. While the market is used to produce the good, one cannot conclude that the aggregate demand for this environmental good can be measured simply by an examination of the increased demand for logoed products. There is no reason to believe that consumers can accurately understand, predict and quantify the amount of environmental benefit which their purchase is generating, and compare it to the increased price, if any, demanded for the good. We may be able to say that the purchase decision is evidence of some demand, but its quantification is impossible. We cannot say, even though the program uses the market to generate the benefit, that the cost of producing the environmental good is less than that benefits it produces, we can only say that the cost is less than the perceived benefits manifested through market transactions.

19 From the perspective of industry taken as a whole, incentive programs represent opportunities to obtain resources from the public treasury. The distributional implications are radically different from those associated with most command models of regulation which create risks of contributing resources to government through fines and other forms of levied charges. The Environmental Choice Program can be analogized to the use of subsidies or tax incentives, but may be unique in that it involves the transfer of a property right which is easily transformable into cash by firms, but is relatively inexpensive to produce by the government. It thus differs in an important way from traditional subsidies and thus may be employed in environmental regulation where subsidies have not. 
program is a market based policy instrument designed to address that market failure. But the program itself is subject to a range of its own second order market failures:

a) the development and distribution of the entitlement might be plagued by informational problems including the non-disclosure by the program of the criteria of eligibility for the entitlement, lack of information about the environmental costs and benefits of the environmental standards and proposed licensed products, lack of information about the shifts in market shares generated by the program, and the inability of consumers to monitor and assess the environmental benefits associated with their purchase of ECOLOGOED products;

b) the development of the criteria for the issuance of the entitlement, as well as individual licensing decisions, might generate negative externalities. These might include the adverse impact of the guideline and issuance of licences on other firms and individuals; and

c) the market for the entitlement might be characterized by situational and market monopolies where environmental benefits may be underproduced, too high a price charged by the government as supplier, and where recipients of the ECOLOGO may be exploited during the term of the licence or on licence renewal.

While procedural due process will not, of itself, correct all kinds of second order market failures, it may indirectly reduce the likelihood of their occurrence. ${ }^{20}$ In other words, the development of fair processes will generate social benefits, not merely private benefits to the licensees. Demanding fair bureaucratic processes should further and not obstruct the achievement of environmental policy objectives through improved definition and allocation of entitlements.

The point cannot be made too adamantly. So long as the legal community attempts to legally coerce bureaucrats through "process control", the best one can hope to achieve is that bureaucrats will establish "fair" processes which they view as necessary evils obstructive, expensive and to be largely ignored in developing and implementing public policy. If, however, it can be argued and demonstrated that fair processes will further bureaucratic objectives, the public sector is much more likely to develop bureaucratic decision-making processes which will be rationally linked to the specific public policy context within which they operate; and which will, in fact, generate views and data which will be considered and thus influence bureaucratic choices. maximizing arrangements. However, it is difficult to imagine the market vehicle which might be used to correct second order market failures in the Environmental Choice Program. 


\section{THE ENVIRONMENTAL CHOICE PROGRAM}

The Environmental Choice Program is an admittedly modest example of an economic instrument designed to regulate corporate and human activity affecting the environment. ${ }^{21}$ Specifically, the program attempts to modify both producer behaviour in product development, and consumer purchasing behaviour, through the governmental development and distribution of a marketable entitlement - the contractual right to use a government owned ECOLOGO.

The program, simplified to an extreme, involves four stages. First, the Environmental Choice Board ${ }^{22}$ selects and tentatively defines a "product category. ${ }^{123}$ Very early on in this process, the Board obtains a "life cycle" environmental impact analysis of the proposed product category. To date, the program has addressed some 50 categories ranging from re-usable diapers, re-refined motor oil, low solvent water based paints, to fine paper products made from recycled fibre.

The second stage of the program involves the development, using the Canadian Standards Association ${ }^{24}$ and voluntary multi-sectoral task forces, of environmental guidelines issued by the Minister of the Environment under the Canadian Environmental Protection Act. The guidelines are based on the environmental impact assessment, are specific to each product category, and address the performance and design characteristics with which products must comply in order to display the ECOLOGO. ${ }^{25}$

As an economic instrument, it is not surprising that it is being employed in purely private initiatives. For example, the American Heart Association has considered developing a heart shaped "seal of approval" and licensing private firms, for a fee approaching $\$ 40,000$, to use the logo on products which have been certified by the Association. The United States Department of Agriculture has actively opposed this initiative, considering it simplistic; and some members of the private sector have called it a "marketing gimmick".

The Board is established under s. 5 of the Canadian Environment Protection Act R.S.C. 1985, c. C15.3 as an Advisory Board to the Minister of the Environment. It consists of 15 persons and a Chair appointed by the federal Minister of the Environment for indefinite terms. Currently the Board consists of representatives of consumer groups, environmental groups, several science and social science disciplines, and industry.

Product category suggestions are sometimes generated internally within the program. More often, the Board draws on suggestions from external sources including, product manufacturers and suppliers, environmental and consumer groups, and individual consumers.

Environment Canada has contracted with the Canadian Standards Association to provide this service. The CSA has substantial national and international credibility in developing consumer and industrial standards. However, the CSA is simply an administrative infrastructure - it provides secretariat services for the task forces which consist of voluntary industry, environmental and consumer, and government representatives. The CSA does not set standards, nor does it engage in research on which the standards are based.

In developing the environmental guidelines, Environment Canada has been guided by a concern that all proposed products and services encompassed by the program will generate a net environmental benefit taking into account the entire life-cycle of the service or product, consistent with the complete product life-cycle concept inherent in the Canadian Environmental Protection Act, supra note 22. 
After the promulgation of the environmental guideline, individual manufacturers, importers or retailers are licensed, for a fee, to use the ECOLOGO. ${ }^{26}$ The most significant aspect of the licensing program involves product testing and confirmation that a particular product or group of products complies with the environmental guideline requirements.

Finally, all licensed users are monitored to ensure compliance with the licence's terms and the environmental guidelines. The term of the licence is one year, and the licensing agreement permits spot audits of manufacturing plants and access to all relevant production and purchase records. Sanctions for non-compliance include contract termination and product recalls, and damage recovery by the government.

In contrast to traditional regulatory instruments, the program does not prohibit private action subject to compliance with mandatory standards enforceable through the administrative or judicial process. No industry participant is required to use the ECOLOGO or to comply with the environmental guidelines. However, the success of the program is based on evidence which suggests that industry will face competitive pressures to do so, and will comply if they believe that the market benefits of the licence exceed the costs incurred to produce products in compliance with the environmental guidelines. ${ }^{27}$ In a very real sense, all aspects of the program acknowledge that the participants control the program's agenda and direction, and thus will determine how the transition to an economy which is linked to the environment will take place.

\section{A CASE STUDY PROCEDURAL FAIRNESS AND THE ENVIRONMENTAL CHOICE PROGRAM}

Procedural fairness describes the set of institutional structures and decision-making processes which permits potentially affected individuals and groups to participate effectively in decisions affecting their interests. ${ }^{28}$ This paper addresses the institutional structures and processes which relate directly to the two classes of major decisions the Environmental Choice Board makes on an ongoing basis. The first - CATEGORY 1

The issue of the fiscal independence of the program is extremely problematic in terms of program effectiveness. The fact that the Program benefits financially through the licensing process creates an incentive to develop lower environmental standards in order to maximize the number of licensed users and thus program revenues. While it is true as explained below in Part 2 that lower standards, (that is standards which generate a somewhat higher EQ) are not per se undesirable, it is true that systems which generate higher EQs present a risk of producing a negative (EC-EQ), which would be undesirable under any conditions.

The Program licensing fee ranges from $\$ 300.00$ to $\$ 5,000.00$ based on annual net sales and thus does not present substantial costs even to small producers.

In theory, concepts of procedural fairness in bureaucratic institutions and processes can encompass all aspects of incentive programs. Fairness issues are presented by the institutional structure of government programs whether they are intra-departmental, utilizing "special operating agency status," or are established as Crown corporations. Fairness issues arise in connection with the processes and criteria for the appointment of regulatory decision-makers. Fairness is affected by access to resources of potential participants. Fairness can encompass disclosure of regulatory policy, criteria and decisions. All program structures, processes and policies which relate to effective participation might, and perhaps should, be assessed in terms of fairness ideals. 
decisions - involves the definition of the "entitlement". These decisions include the choice of a specific product category, the development of its related environmental guideline, and the negotiation of the substantive terms of the licensing agreement. The second CATEGORY 2 decisions - involves the allocation of the entitlement to a particular applicant. This category includes the licensing and de-licensing of particular manufacturers to use the ECOLOGO. ${ }^{29}$

The critical constituent elements of procedural fairness in both categories are access to information, ${ }^{30}$ effective participation in decision-making, ${ }^{31}$ and appeal and review processes. ${ }^{32}$ The program has, from the outset, attempted to afford potentially affected parties considerable opportunity to participate in both categories. Faimess considerations have been used to justify access to information, opportunities for effective participation, and recently, the development of several review processes. More importantly, one can identify a significant trend towards an expansion of these process rights as the program has matured.

\section{A. CATEGORY ONE DECISIONS}

It is difficult to predict whether a court would say that Category 1 decisions - the development of voluntary guidelines under the Environmental Choice Program and the substantive content of the licensing contract - trigger procedural faimess obligations on

Both the private value of the entitlement (the net benefit to producers of the right to use the ECOLOGO), as well as the social value of the entitlement (the net environmental benefit produced by product substitution), are established by the combination of CATEGORY 1 and CATEGORY 2 decisions.

Informational issues in environmental standard setting are extremely complex. First, many of the Board's decisions are founded on scientific data which is the subject of debate within the scientific community itself. Second, the information base is not static. With decisions evolving over a 12-18 month period, one has to develop procedures to ensure ongoing review and updating of the information base of those decisions. Third, disclosure of extremely complicated technical information to non-experts is an exercise in futility, and thus one must address the translation of that information both within the program and to affected parties. Fourth, the information which is the subject of disclosure is extremely varied, relating to the environmental impact analyses on which the guidelines are based, the use of single or multi-factorial sets of criteria by the Board, and the weighting, rank or emphasis which the Board is placing on certain environmental benefits or risks. Finally, the Board as part of Department of the Environment is subject to the limitations on disclosure established under the Access to Information Act R.S.C. 1985, c. A-1.

31 Here, the Board has taken into account the identity of the parties to whom information must be disclosed, the disclosure of reports while in draft form, the use of informal consultative processes, concerns with equal access both within industrial sectors and between industry and environmental groups, and the delegation of decision-making authority to subordinate groups within which multisectoral representation is ensured.

Appeal processes can be established both at the initial guideline setting stage and in respect of individual licensing and licence termination decisions. In both cases, one must assess whether the appeal should be internal or external to the program, the identity of the appellate decision-makers, the grounds of appeal, standing requirements, and the unavoidable existence of bureaucratic and political review. 
the part of the government and thus the Board. ${ }^{33}$ However, as suggested earlier, the Board has made a deliberate choice to incorporate substantial procedural fairness in respect of all of the constituent elements of CATEGORY ONE decisions.

In deciding which product categories are to be addressed in the Program, a wide ranging consultative process through the Canadian Environmental Network has been initiated. This process communicates requests for product categories to hundreds of nongovernmental environmental groups across the country. Similar initiatives have been taken with industry trade associations. These two institutional initiatives have been linked to more diffuse public information programs through which the same request has been made $^{34}$ As well, the Board has disclosed the criteria which it employs in selecting product categories for preliminary investigation. ${ }^{35}$ Although a statistical analysis of the ratio of product category suggestions to completed guidelines has not been carried out, at least $90 \%$ of the final guidelines have their source in one or more public suggestions. ${ }^{36}$

Second, the Board, in producing a life cycle environmental impact assessment of each proposed product category, has actively searched out technical, scientific, environmental, and market related information from both public interest groups and specific industry members. ${ }^{37}$ Improved procedures which the Board is seeking to implement would ensure that all of the information comprising the environmental impact analysis is reviewed by potentially affected parties as early on in the process as is possible - including its developmental stage.

Third, from the outset of the program, the Board has disclosed the general criterion which it has employed in making its decisions on the detailed content of environmental guidelines:

While these decisions rank as a senior multi-factorial policy decision in the hierarchy of decisions which the Board makes, the cases make it clear that if representations are made by public bodies, they may be protected through administrative review processes regardless of the level of government which engages in the information disclosure. See $\mathrm{Ng}$. v. Attorney General for Hong Kong, supra note 9.

These programs include a newsletter, as well as numerous in person and electronic media presentations by program staff and Board members. A complete list of the presentations is available from the ECP. See Minutes of ECP, September 10, II 1990, Montreal, Quebec.

Thesc criteria, in rank order of importance, are expected environmental benefits, market considerations, technical feasibility, salience, timing, and strategic leadership. Discussions at the original Board meeting indicated that the first two factors are substantially more important than the final four.

36 - The original and extremely tentative choice of potential product categories clearly creates "potential" winners and losers in the regulatory process. But at this stage, participatory rights would be very problematical. Many selected categories are not pursued. Absent a vehicle to identify potentially affected parties (impossible without first knowing what the environmental impact analysis might contain) procedural rights would be an exercise in futility. Nonetheless, given the importance of identifying interested parties at this early stage of the process, recommendations have been considered by the Board to issue a notice of our intention to investigate proposed categories through mass media and the Canada Gazette.

37 The Board does not use internal staff to prepare the environmental impact analysis, but contracts out the work to environmental consultants. Explicit instruction is given to the person preparing the report to consult with industry in the preparation of the report. 
The product, service, process or packaging, when compared with other products, services and packaging fulfilling the same function, and when taken its entirety, must be characterized by a particularly high degree of environmental soundness taking into account product performance and safety.

It is true that by itself this vague criterion is unlikely to offer potentially affected parties sufficient information to permit effective participation in program decision-making. Nonetheless, it remains an important aspect of procedural fairness in three ways. First, it discloses that, while economic impacts cannot be ignored given the use of markets in generating environmental improvements, the Board does not engage in "trading off" environmental improvement for economic concerns. Second, the criterion discloses that the guidelines are intended to ensure that product performance and safety are not unduly sacrificed for environmental benefits. Finally, the precise product characteristics which will generate the anticipated environmental benefits - necessary information to all potentially affected parties will be disclosed through the environmental impact analyses discussed above.

Fourth, in constituting the task forces in which specific environmental guidelines are developed, the Board has attempted to ensure representation by industry participants whose interests may not coincide, by a range of consumer and environmental groups, as well as by independent experts. This process is supported by the creation of a "Coordinating Technical Committee" (CTC) responsible for the operation of the task forces. The CTC consists of independent experts; a CTC member chairs each task force; and part of the responsibility of the CTC chair is to ensure that affected groups are represented at what is perhaps the most critical stage of decision-making in the program - the development of the substantive content of the environmental guidelines by multisectoral task forces. ${ }^{38}$

Fifth, all environmental guidelines are published in draft and then final form as Ordersin-Council under section 10 of The Environmental Protection Act in the Canada Gazette. Thus a formal comment period of at least 60 days is afforded to all members of the public. This formal notice and comment process, while it might appear to come too late to have a significant impact on the substantive content of the guidelines, is far from a procedural sham. The Board has designed a process which generates a report from the program Secretariat which summarizes all received comments, with the submitter identified, when it considers each proposed guideline for final recommendation to the Minister of the Environment. Again, while statistics are not available, a significant percentage of guidelines have been modified in significant ways between the draft and final recommendation to the Minister. ${ }^{39}$

While the Board does not hold formal hearings in the guideline development process, it has, in the formulation of the "Sanitary Paper from Recycled Paper" guideline, established a sub-committee of the Board to receive a submission from a particular manufacturer and to report to the Board on the substance of the submission which was directed to the content of the proposed guideline. the general guideline requirements. For example, comments from the West Coast Environmental Law Association resulted in personal meetings between WCELA representatives and a Board representative, and in modifications to the guideline which relate to CEO attestation of compliance with environmental legislation by licensed companies. 
Sixth, final decisions on all environmental guidelines are made by the Minister of the Environment on the advice of the Board under section $8(1)$ of the Canadian Environmental Protection Act. There is not now any formal internal appeal process which might be used by adversely affected parties to challenge the recommendation of the Board to the Minister in respect of a particular guideline.$^{40}$ But one must recognize that at least some affected parties will attempt to influence the Department through submissions to senior line bureaucrats, to other departmental bureaucrats or to Ministerial staff, and thus attempt to influence the Minister of the Environment not to accept the Board's advice."

The Board has addressed this issue through consultations with the Department, through signals to the Minister describing the importance of solidarity between the Department and Board, and most importantly through the development of the procedures described above which assure the Minister of the procedural fairness and technical rigour of the Board's work.

The Board is currently designing an internal review process which would permit an affected party to seek a Board review of its recommendation based either upon information which was unavailable at the time the relevant task force developed the substantive content of the guideline, or on procedural fairness grounds. ${ }^{42}$

The final stage in the definition of the entitlement created by the Environmental Choice Program is the process by which the substantive content of the licensing agreement is determined. As described above, the set of contract terms together with the environmental criteria in the environmental guideline define the program entitlement. The original licensing agreement involved modifications to a standard Canadian Standards Association licensing agreement, which was carried out in "private" by the Board, Justice Department advisors, and legal advisors to the Canadian Standards Association. The degree of public participation in developing the contract was minimal. ${ }^{43}$

The substantive terms of the licensing agreement to use the ECOLOGO generate the bilateral benefits characteristic of exchange transactions. However, this contract, like all contracts, permits both parties to exercise power, in their own interests, against the other.

Even more difficult would be the development of appeal rights in respect of "decisions" not to make recommendations to Ministers. To companies which would otherwise benefit from the creation of a product category, the decision to not act is as significant as the decision to make the recommendation. In a significant number of cases, however, the inaction is a product of benign neglect rather than deliberate focused choices. The absence of a decision which would trigger the appeal process renders formal appeal rights somewhat difficult to implement.

This in fact has happened on at least one occasion where an unsuccessful, but extremely vigorous lobbying effort was undertaken by a specific company and trade association in an attempt to persuade the Minister of the Environment to refuse to sign the Order-in-Council creating the guideline. The existence of this "appeal" right is beyond the operational control of the Program given the Advisory Board status of the Board, and the current requirement that the guidelines be published as Orders-inCouncil.

The procedure would involve notification of all parties who participated in the original guideline development process.

43 Two Board members from the private sector were asked to assess the terms in light of their experience and sectoral interests. 
Procedural safeguards applied to the exercise of contract power might be derived either from private contract law "fairness" doctrines ${ }^{44}$ or from public law "due process" requirements. Fairness review will involve either an assessment of the monopolistic nature of the market in credible environmental logos, ${ }^{45}$ or explicit judicial review of at least some of the substantive terms of the contracts where the government is a party to the transaction. ${ }^{46}$

At this point in the program's evolution, it is clear, regardless of any legal obligation to involve affected parties in the original contract drafting process, that the program would have benefited from that involvement. The program entitlement defined in part by the contract terms is not optimal, and thus the program has commenced the process of modifying the standard form contract language employed in the licensing agreement. These modifications were initiated simultaneously by a suggestion from a potential licensee ${ }^{47}$ by the Board, ${ }^{48}$ and through consultation with a public interest environmental group. ${ }^{49}$

Because of the value to the program of involving as many segments of the various "publics" as possible in the program's decision-making processes, and because modifications to the contract will, in effect, constitute a "renegotiation" of the licensing arrangement with current licensees, several procedures have been initiated to encourage

Concepts of procedural due process have only rarely been applied to regulate the bilateral negotiation of contract obligations in the private sector involving commercial arrangements between sophisticated parties such as are likely to be found negotiating with the government in the Environmental Choice Program. Procedural due process in market transactions has been developed by the courts through the application of common law concepts of unconscionability and "unfair surprise" which have been employed to regulate the procedural environment under which exchange transactions take place. With relatively sophisticated industry participants, assessments of the procedural fairness of the contracting process in the Environmental Choice program will likely not involve informational concerns. Moreover, there is little evidence that the courts could adequately assess the competitive environment within which the program operates, and even if they could, the program design demands that the government must offer benefits through the logo/contract combination which exceed compliance costs to the private sector licensees.

In a recent decision, the Supreme Court of Canada in Board of Education of the Indian Head School Division No. 19 of Saskatchewan v. Knight, [1990] I S.C.R. 653, held that the consideration of the fairness obligations of government in its role as contractor, must go beyond interpretative contractual analysis to "encompass arguments of public policy." Madame Justice L'Heureux Dubé said that the substantive fairness of the contract termination provisions would be subject to judicial review, independent of any procedural unfairness in the contract negotiation process.

In particular, a potential licensee which manufactured paints was concerned with the termination powers allocated to the government in the contract.

Analysis of the contract language has led to two concerns. First, the automatic renewal of the annual licence presents a greater risk of judicial review on the basis of a "legitimate expectation" argument, than would automatic termination coupled with an implicit and perhaps expedited renewal process. Second, the discretionary termination rights enjoyed by the government in response to a breach by the licensee might give rise to bureaucratic or political obstruction, as compared to the effect of an "automatic" termination provision.

49 The West Coast Environmental Law Association, with other submitters, suggested that the terms of the Guideline were ambiguous in relation to both CEO attestation of compliance with environmental legislation and with the consequences of non-compliance with the legislation. Some of those concerns are addressable through the terms of the licensing contract. 
public input in the contract redefinition process. ${ }^{50}$ First, notice of the draft agreement will be published in several trade journals and newspapers. Second, the Canadian Environmental Network and industry trade associations will be utilized to distribute copies of the draft agreement to interested parties. Finally, current licensees will be consulted on an individual basis to discuss with each of them the contractual modifications which are being considered - affording them notice of the change at an extremely early stage in the process, and the opportunity to contribute to the final product.

\section{B. CATEGORY TWO DECISIONS}

It is difficult at this stage in the evolution of the Program to describe the process employed in CATEGORY 2 decisions - the allocation of the entitlement through the licensing and de-licensing of manufacturers to use the ECOLOGO. So far, the program has generated numerous CATEGORY 1 decisions which have led to the development of many of the procedural components described above. However, the program has very little experience with contentious licensing applications, and has yet to de-license or fail to renew a licence. ${ }^{51}$

Several recent decisions suggest that judges may not be overly sensitive to claims that the receipt of government benefits either through employment contracts or direct grants generate procedural fairness obligations on "legitimate expectation" grounds. ${ }^{52}$ Nonetheless, important procedural components have been incorporated in this aspect of program operations, and again it is Board policy that this ought to be done irrespective of legal requirements to afford procedural fairness to potential or actual licensees. ${ }^{53}$

So long as notice and procedural fairness is provided, there does not appear to be an insurmountable problem with "changing courses in mid-stream." However, there are certainly remarks in several of the "legitimate expectations" decisions which suggest that government agencies cannot depart from "undertakings" except after affording affected parties procedural fairness and if satisfied that the overriding public interest requires the departure. That latter requirement would transform a pure process right into something radically different. See $R$. v. Liverpool Corporation, [1972] 2 All E.R. 589 per Lord Denning at 594; $R$. v. Secretary of State, Ex Parte Kahn, [1985] I All E.R. 40 per Lord Parker at $46,48$.

sI With one exception, all applicants have been licensed or been refused a licence without engaging in any serious debate over their right to use the ECOLOGO. That is, the application of our rules (environmental guidelines) to the specific facts of an applicant's manufacturing process or product has given rise to only one case which while not close to the line, did present the Program with a situation which it had not contemplated. In that case, a manufacturer of garbage bags made from recycled plastic applied for a licence to use the ECOLOGO in accordance with ECP-03-1990 "Plastic Products from Recycled Plastic." Program staff quite correctly anticipated that the Board, when it developed the guideline, had not considered that it might be applied to garbage bags, a product which the Board might not want to be part of the program for a number of reasons. The manufacturer was asked to defer its application while the matter was considered by the Board.

See Toronto Independent Dance Enterprise v. Canada Council (1989) 38 Admin L. R. 231 (F.C.T.D) (no procedural fairness applicable to non-renewal of government grant); Rainbow v. Central Okanagan School District \#37 (1988), 10 B.C.L.R. (2d) 137 (B.C.S.C) (no fairness obligations in respect of non-renewal of employment contract).

53 There is little doubt that, in some cases, the "contractual" power exercised by the state will be subject to the same kinds of procedural constraints as legislative and regulatory authority. See $R$. v. Secretary of State, Ex Parte Kahn, supra, note 50; Council of Civil Service Unions and others v. Minister for 
Important faimess considerations arise during the earliest stages of the licensing process. There is some authority for the view that the government owes a duty of faimess which requires it to "consider and analyze an application which has been made"..$^{54}$ The program has, apparently, deliberately considered every application to determine if the applicant's product or service comes within the product category definition.

The second stage in the licensing process, after tentative approval of the application by the Canadian Standards Association, is the verification by CSA employees of compliance by the applicant with the requirements of the environmental guideline. To date, no applicant has been refused a licence and disputed either an interpretation of a guideline, or the facts determined by the CSA in its verification process. This may be due to the considerable expertise enjoyed by the CSA in this area, coupled with the considerable involvement of the private sector in developing the substantive criteria contained in the guideline. Nonetheless, it is likely that the program will develop an internal review process to assess both interpretative and factual disputes in this context.

The program's final decision-making process involves decisions to modify, terminate or fail to renew existing licences. There are three ways in which licensees may be able to develop "procedural fairness" arguments in this context..$^{55}$ First, they might argue that the licence itself should be interpreted as providing for procedural fairness - the content of procedural fairness in this context will be decided, in part, by reference to the terms of that contract. ${ }^{56}$ Many procedural rights are created as contract dispute resolution terms in the licensing agreement which "regulates" contract termination and renewal as part of the contractual relationship between the government and the licensed users.

The contract now employed may provide some foundation for the argument that procedural fairness should be afforded applicants in the case of termination or nonrenewal of their licences. ${ }^{57}$ Clause 8.2 of the contract permits immediate termination by

the Civil Service, [1985] 1 A.C. 374 at $409-10$.

In a recent decision, the Trial Division of the Federal Court refused to permit the Ghermezian brothers to continue their participation in a tendering process for a $\$ 200,000,000$ contract to build Transport Canada's new headquarters. The plaintiffs brought an action to require the Minister of Public Works to evaluate a bid which they had submitted through two holding companies: Calmar Quebec Ltee and Les Placements Alize du Quebec. See Globe and Mail, Report on Business (27 April 1989) at B11. Similarly, in Jim Harris Lid. v. Minister of Energy, supra note 9, the New Zealand High Court held that review of statutory powers could apply to the case of a disappointed contractor who had unsuccessfully tendered on a government contract.

A fourth source of procedural fairness arguments is statutory language which might be viewed as requiring either certain procedures in the licensing process, or as demanding certain substantive license terms. There is nothing obvious in reading the Canadian Environmental Protection Act supra note 22 which might be used to justify this kind of claim. description of CATEGORY ONE decisions. "interpretation" so as to afford the private sector considerable protection from government "renegotiation" of contract terms. Thus in Webster v. Auckland Harbour Board, [1983] I N.Z.L.R. 646 at 650 the New Zealand Court of Appeal held that the defendant in attempting to increase the rent charged for a waterfront lease from $\$ 1.00$ to $\$ 640.00$, "in exercising contractual powers, ...may also be restricted by its public law responsibilities". 
the government for breach of any of the contract or guideline terms, or on 30 days notice without cause. There are no appeal rights in the contract, although clearly a licensee would have the right to sue the government for breach of contract if it could demonstrate that the government was not contractually entitled to terminate. However, the standard form guideline contemplates an appeal from a decision to terminate for non-compliance with environmental legislation. Clause 9.3 of the contract provides that the license to use the ECOLOGO will be renewed automatically unless terminated, but is silent on the process which might be employed to determine to not renew a licence. Finally, the contract is silent on the procedure which the government may use to terminate a licence for non-compliance with the licensing terms or with associated environmental guidelines. ${ }^{58}$

A second source of "procedural unfairness" in the licence renewal or termination process arises from the potential conflict between licensee expectations derived from information received from program staff, ${ }^{59}$ which is inconsistent with explicit contractual language. While that issue has not arisen in a CATEGORY 2 decision, the program has had some experience with allegations that program staff have misdescribed the criteria employed in the entitlement definition process.

The third and final source of procedural fairness in this stage of the Program derives from judicial "due process" directives which are not subject to contractual modification. At least one recent decision has held that the consideration of the fairness obligations of government in the context of employment contracts must go beyond interpretative contractual analysis to "encompass arguments of public policy".60

The program is currently addressing these concerns in several ways. First, the program is currently considering re-designing the contract to reduce the ambiguity associated with the "substantive entitlement" issue and the re-application process. The substantive entitlement issue - whether the contract should be interpreted as an ongoing licence subject to an annual option to "terminate" or an "annual" licence subject to a right to apply for another licence is being resolved in favour of the latter. As well, the reapplication process is being explicitly defined as identical to the original application process. ${ }^{61}$ Finally, the program is evaluating provisions providing for automatic termination of the licence for breach of the contract terms or for non-compliance with the environmental guidelines, coupled with explicit appeal rights on termination or non-

As described above, in a recent decision, the Supreme Court of Canada in Board of Education of the Indian Head School Division No. 19 of Saskatchewan v. Knight, supra note 46, held that the substantive fairness of the contract termination provisions would be subject to judicial review, independent of any procedural unfairness in the contract negotiation process. The Court held further that contractual silence will not be considered a waiver of the application of the duty to act fairly. And any other governmental source of program information.

w) See, Board of Education of the Indian Head School Division No. 19 of Saskatchewan v. Knight, supra note 46. There is no indication that "public policy" means the achievement of program objectives!

61 Subject only to retroactive operation to ensure that the licence will always continue in effect notwithstanding delays in the re-application process. 
renewal. The appeal rights will be linked to notice of the grounds for termination, ${ }^{62}$ and the development of remedial measures considerably short of licence termination. ${ }^{63}$

Unfairness which occurs where licensee expectations are derived from extra-contractual information are being addressed through the development of a centralized information and communication program, staff training, program structures which establish a limited group of bureaucrats as authoritative sources of contractual information, and by contract terms which efficiently shift the risk of conflicting information from the government to the private contracting party. ${ }^{64}$

Government incentive programs, and in particular the Environmental Choice Program, represent potentially effective market based alternatives to command models of state action. The procedures employed in implementing those programs, if they are to duplicate the success of their predecessors in the private sector, should be consistent with market based ideals - considerable information about the other party's expected behaviour, recognition of third party effects in the contract, and significant participatory opportunities in the self-definition of entitlements and as well as in their allocation.

\section{THE PROGRAMMATIC BENEFITS OF PROCEDURAL FAIRNESS}

In Part II, I argued that, in theory, the kind of information required to produce effective public policy demanded substantial and meaningful public participation in program decision-making processes. In Part III, I described the way in which that thesis has been implemented in the Environmental Choice Program's operations. In this Part, I develop in more detail the range of ways in which effective participation by environmental groups, independent scientists and the relevant industry, has contributed significantly to the ability of public bureaucrats to further the public policy objectives of the Environmental Choice Program.

\section{A. ACHIEVING STRATEGIC PROGRAM OBJECTIVES}

What should be obvious from what has been said so far is that offering opportunities for participation serves several strategic bureaucratic objectives. ${ }^{65}$ Open invitations to

A response which will reduce the risk of innocent bureaucratic errors, and misinformation. See Council of Civil Service Unions et al. v. Minister for the Civil Service, [1985] A.C. 374 per Lord Diplock at 408 (requirement of communication of some "rational ground" for withdrawal of benefit). However, affording the private sector ex post appeal rights may not meet judicial definitions of procedural fairness. The Supreme Court of Canada in Board of Education of the Indian Head School Division No. 19 of Saskatchewan v. Knight, supra note 46, held that the statutory right to an investigation of and an appeal from an employment termination decision did not displace the unfairness of an original decision without a hearing. See also, Malloch v. Aberdeen Corp., [1971] 2 All E.R. 1278 (H.L.) per Lord Wilberforce at 1297.

ot See A. Schwartz and R.E. Scott, Sales Law and the Contracting Process (Mineda N.Y.: Foundation Press, 1982) at 46-62.

65 The strategic advantages operate both out and down to the private sector, and inward and up to Environment Canada and the Minister of the Environment - I discuss the internal strategic advantages in Part V. F. 
environmental groups and industry to participate permits the program to identify, at a very early stage in the development of environmental guidelines, self-proclaimed potentially affected groups and firms. The participation of these groups facilitates the development of environmental guidelines which represent unanimous consensus positions at best, and acceptable compromises at worst. ${ }^{66}$ Early identification also reduces the risk of holdout strategies by the private sector, whose participation in developing the guidelines, in applying for licences, and in marketing "ECOLOGOED" products is critical to the success of the program. ${ }^{67}$ Participatory rights engage the political support of potential beneficiaries, and perhaps some potential losers, early on in the decision-making process.

\section{B. IMPROVING BUREAUCRATIC ACCESS TO INFORMATION}

Participatory rights recognize that the role of industry and environmental groups on CSA administered "task forces" is critical to the success of the program. As described above, an important role of each task force is to redefine the boundaries of product categories, and to develop associated performance and design criteria which comprise the environmental guideline. Equally important is the ongoing input of task force participants into the product specific environmental impact analysis which, while initially prepared within the program, is constantly improved upon in light of information generated in the work of the task forces. Finally, industry input is essential to an analysis of the relationship between the substantive content of the environmental guidelines and sales of ECOLOGOED products necessary to optimize program environmental benefits taking into account environmental as well as market variables. Put simply, task force participation generates substantial benefits to the achievement of program objectives represented by increased accuracy, currency and comprehensiveness of the information base upon which program decisions are made. ${ }^{68}$

I explained in Part II the reasons why industry participation is necessary to generate the market analyses upon which program decisions must be predicated. In addition, there are several reasons for believing that the environmental impact analyses are likely to benefit from high levels of participation during the guideline development process. The assessments, which are prepared by consultants on a contract basis, may be originally imperfect for several unavoidable reasons. The consultants must work within extremely

66 Consensus decision-making may mean that the environmental guidelines are more likely to address and reduce possible negative externalities generated by the program. The optimal process would ensure that the substantive content of the guidelines reduce to a minimum the costs associated with their implementation and maximize net expected environmental benefits. While that ideal is unachievable, open decision-making processes are more likely than closed processes to move the program in that direction. See Part II.

68 Of course, there are strategic benefits associated with increased accuracy of information. As one industry representative put it - they would prefer not "to defend the industry's position by responding to errors or half-truths in our documentation public; better that we get the best input in the early days from all sources than have both parties embarrassed by poor information." 
limited time constraints. ${ }^{69}$ This constraint recognizes that the Board will, in a significant number of cases, conclude on the basis of the original assessment that the development of an environmental guideline is not justified. It is simply impossible to know at the outset whether certain ideas have sufficient merit to justify additional work. The enormous diversity of product categories which the Program must address, ${ }^{70}$ means that the data and even the methodology employed on an environmental impact assessment on one category will rarely be transferable to another. This problem is exacerbated by the apparent absence of an accepted methodology for producing "life cycle" environmental impact analyses of suggested consumer products. Procedural fairness affords bureaucrats access to scientific as well as market information necessary to develop optimal environmental guidelines.

\section{IMPROVING GUIDELINE DRAFTING}

Effective participation furthers the guideline drafting process in several ways. Participation of a broad range of interests in the guideline development process produces regulatory language which is less ambiguous than would otherwise be produced. The reduction in ambiguity is derived from the identification of environmental variables which might otherwise be left unarticulated, from the explanation of industry specific terms which have accepted "trade usage" meanings, and from the development of a recorded negotiating history to which reference can be made at later times. Clarity in guideline drafting reduces misunderstandings which can lead to inadvertent non-compliance, and the development of clear directions to industry will reduce monitoring and enforcement costs.

\section{LEGITIMATION OF PROGRAM DECISIONS}

Participation by affected groups legitimates the decisions reached by the task forces and thus the Board. Legitimation - the acceptance of the guidelines as authoritative and deserving of respect independent of formal enforcement power - is derived from effective participation which transforms the authorship of regulatory decisions. Without participation, bureaucratic decisions are perceived by industry as a product of a set of exogenous values imposed by public bureaucrats. With participation, program decisions become decisions made by the community of interests and parties affected. Industry participants are more likely to respect their own decisions as compared to their response to decisions imposed by others. The participatory processes are all designed to generate the sense of consent to, and ownership in the program decisions necessary for effective government.

The program permits the consultants about two months to complete the environmental impact assessment. At present the delay between an original product category suggestion and licensing decisions, commonly approaches one year. It is thus imperative that the preliminary environmental impact assessment not contribute to additional delays.

To date, the program has developed environmental guidelines for, batteries, re-refined motor oil, unbleached paper products, ethanol based gasolines, diaper services, heat recovery ventilators, low solvent water based paint, recycled plastic products, among others. 


\section{E. REDUCING ENFORCEMENT COSTS}

Associated with legitimation is a fifth programmatic benefit a substantial reduction in monitoring and compliance costs. While one would be naive to assume that industry will, without the threat of licence withdrawal, comply with licence and guideline terms, participation in the guideline and contract development process will reduce the incentive to violate the contract terms in number of ways. ${ }^{71}$ Enforcement costs are reduced through the reduction in ambiguity in the guidelines derived from the involvement of industry in their development. Monitoring and compliance costs are further reduced where industry participants believe that they are complying with requirements which they themselves proposed, worked on and approved. Enforcement costs are reduced where licensees are fully aware of the substantive content of the guideline as a result of their involvement in developing the guideline criteria. Finally, enforcement costs are reduced as the substantive benefits to the licensee increase, presenting increased downside risks if they were to have the licence revoked for non-compliance.

\section{F. ENHANCING BUREAUCRATIC POWER}

Exercising bureaucratic power is, except to the strictest of positivists, much more than deriving legislative authorization from a constituting document. Rather, exercising bureaucratic power means generating the political support of a broad range of related private and governmental interests. In the case of the Environmental Choice Program that means generating the support of line bureaucrats in Environment Canada, Ministerial staff, major industry actors and major environmental groups. Creating process rights furthers this internal bureaucratic strategy in several ways. Affording public interest groups and industry the opportunity to participate at the program level reduces the chances and opportunity for those parties to demand the attention of line bureaucrats. A record illustrating effective participation can be employed to persuade Ministerial staff that complainants have been "treated fairly" in the program, and that the scientific basis for the Board decision is defensible. ${ }^{72}$

Many of these points have been discussed in Part II, where the program benefits of effective participation in Category 1 decisions were described and analyzed in detail. ${ }^{73}$ They can also be appreciated through a brief examination of the array of individualized

As well, the licensing fees shift the marginal costs of monitoring and enforcement associated with a particular licensee to that licensee, rather than allocating those costs to general administrative or overhead costs.

The appeal process which would permit an affected party to seek a Board review of its recommendation on an environmental guideline is being developed to provide those assurances during the Ministerial approval process.

One way to understand regulation is to conceive of it in purely informational terms - regulation describes the phenomenon of informing persons of the consequences of their behaviour. The earlier in the regulatory process one can generate the information, the sooner one can expect industry to comply. Early disclosure of government policy - through the distribution of environmental impact assessments, participation on task forces, disclosure of reasons for decisions to terminate licences, and so on - influences private sector conduct much earlier in the regulatory process than would occur if the decisions were only disclosed once they were final. 
procedural rights afforded potential and current licensees in Category 2 decision-making all of which, on their face further only the interests of the private industry.

Procedural protection in the original application process reduces the risk that potential licensees might be precluded from participating in the program without a review of the environmental benefits associated with their products. As well, the process generates valuable information which facilitates the development of more effective monitoring and compliance processes which can be applied to other applicants. And consideration of applications has generated ideas for related product categories with somewhat different environmental guidelines where applications have been considered and then temporarily rejected.

Procedural fairness in the licensing process significantly reduces the risk of contract litigation by initiating an independent assessment of contract and guideline compliance prior to final contract termination. This reduction in the risk of substantive contractual challenges to government action is coupled with a reduction in procedural challenges using administrative law concepts. ${ }^{74}$

Most important, procedural protection in the licensing context increases both the private and social benefits of the program. The private value of the entitlement to the licensee is increased through a reduction in the risk of government action unrelated to compliance. As the private value of the entitlement is increased, the program can demand greater environmental benefits in the substantive content of its guidelines. The existence of an appeal right generates further environmental benefits where it identifies licensees which ought not to have their entitlement terminated. ${ }^{75}$

Finally, notice and appeal rights may permit the program to negotiate less Draconian solutions to non-compliance which permits licences to continue in effect. Enjoying the ultimate power to de-licence, if that is all one has, presents the regulator with a difficult and delicate game of "chicken" with members of the regulated industry. As with many regulatory programs, Environmental Choice Program regulators need licensed manufacturers as much as the licensee needs the regulators' continued consent to use the ECOLOGO. Understood in this way, simply giving the regulator the power to terminate the licence, and no more, is unlikely to generate optimal enforcement decisions. Fairer termination provisions permit flexible and situation-specific responses to non-compliance which can simultaneously address non-compliance and continue the production of environmental benefits through sales of ECOLOGOED products.

74 Litigation is not simply undesirable because we might lose a challenge to a particular licensing decision. Much more important is that litigation re-directs substantial Board and bureaucratic resources away from program objectives towards dealing with the lawsuit. Much more important than losing is that litigation is virtually the last thing that a Minister wants to see in her political future. Much more important than losing a particular case is that losing will signal dozens of other parties of a potential weakness in the bureaucratic resolve which can be exploited. Much more important than losing is that litigation, and the issues addressed in courts, are at best poorly understood by program staff who are effectively disempowered once the threat of litigation is raised. 
This remarkable combination of programmatic benefits associated with procedural faimess is not, however, the only way to assess the development of the Environmental Choice Program. In the next Part, I briefly explore several possible justifications for imposing limitations on process rights.

\section{CONSTRAINTS ON FAIRNESS}

While procedural fairness furthers program objectives, it does not do so without costs. Defining the limits of fairness in government incentive programs depends on the original justifications for creating fairness obligations. Utilitarian justifications suggest that investments in faimess ${ }^{76}$ should be made only until the marginal cost of fairness just about equals the marginal benefits generated by the development of procedural rights. As an empirical question, that is likely unverifiable. But the experience of the Environmental Choice Program suggests that the costs, even with the substantial investments now being made, are justified. As well, the Board in designing its procedures is cognizant of delay costs and is developing conditions on participation in an effort to reduce the risks that parties can exploit procedural rights for strategic advantage. ${ }^{77}$ Finally, a significant portion of process costs is privatized through the non-subsidization of industry participation in enhancing the market and scientific information on which the guidelines are based, and through the partial allocation of program costs, through the fee schedule, to specific licensees.

Program designers who are cognizant of the costs of procedural fairness can attempt to maximize the benefits of participation by instituting processes which are linked to the achievement of program objectives, by privatizing some portion of those costs, and by defining process rights so as to reduce strategic delay opportunities.

A second constraint on fairness relates to the ability of the program to modify its structure and decision-making processes on an ongoing basis. What has made the program as "fair" as it is, has been the Board's willingness to operate without an administrative manual, and to respond quickly and effectively to events in each stage of the program's operations. There is a considerable risk that benefits associated with this flexibility will be compromised if "fairness" is blindly defined as acting as others would expect in light of inferences derived from past behaviour or from explicit representations about future actions. ${ }^{78}$ This risk is exacerbated by the multi-sectoral nature of the program which consists of a diverse Board of Directors, internal program staff seconded from Environment Canada, Environment Canada bureaucrats, the Minister's staff, the Canadian

The investment costs include incurred expenses which would otherwise be employed in other aspects of the program, Board and staff time and effort, and delays in generating guidelines and licensed products in consumer markets.

$n$

For example, the right to a review of environmental guidelines will likely be limited to a right to present information which was unavailable at the time the relevant task force developed the substantive content of the guideline, and to present procedural unfaimess arguments. It is not a review of the merits of the decision, nor a review of the information on which the decision was based. Tullybelton at 401 (legitimate expectations might arise from either regular practice or explicit representations). 
Standards Association, temporary task forces comprised of multi-sectoral volunteers, and a Coordinating Technical Committee comprised of independent scientists. The idea that this amalgam of personnel and institutions could generate one clear consistent message over time is likely unattainable.

The final constraint on "fairness" recognizes the contradiction between participatory rights enjoyed by an abstract public, and the political reality of public administration. The asymmetric distribution of information among affected parties, the ability of industry to recapture some of its costs of participation, and the incentive of industry to participate given the highly focused gains and losses generated by the program combine to create a significant risk that industry might "capture" the program through domination of its task forces and control of its information base.

The solution to this risk is, paradoxically, more participation. Industry, like the environmental movement, is not homogeneous. In the case of competitive industries, the Program has attempted to ensure the participation of smaller, entrepreneurial enterprises who have the incentive and information resources to expose the weaknesses in the data and arguments of the major industrial participants. Similarly, the Program has attempted to ensure the participation of the non-industrial sector through the funding of environmental and consumer organizations. Effective participation in task forces requires substantial expertise and the investment of considerable valuable time by volunteers. Unlike the private sector, the gains from that participation are not enjoyed privately by public interest groups, and thus one cannot argue, as in the case of industry participants, that those gains ought to be used to fund the intervenor's costs. ${ }^{79}$

\section{CONCLUSION}

The Environmental Choice Program, like many government incentive programs involves ongoing contractual relations, and is designed to achieve environmental policy objectives through the allocation of direct benefits to private sector parties. One characteristic of those kinds of relations in private markets is a concern with one's reputation among existing and future partners, and a substantial element of cooperation between the participants in market transactions. Government bureaucrats have not necessarily been concerned with reputation effects and the generation of cooperative arrangements between themselves and the firms whose behaviour they are attempting to influence.

My thesis is that incentive programs, like the more successful market transactions which occur in the private sector, will succeed as the government and the private sector

The program has recently developed a policy to fund the travel and accommodation costs of public interest intervenors, as well as the costs of engaging experts to assist them on task force guideline development work. The task of selecting the subset of applicant public interest groups has been delegated to a small coordinating group who will recommend the funding of groups which have a clearly defined interest and subject matter expentise in the product category or environmental issue being addressed. We have not yet made the critical "first order" decision regarding the absolute or relative amount of our program budget which will be allocated to that funding program. 
establish cooperative solutions to exploit joint opportunities. With time, these relationships strengthen, mutual benefits increase, and default risks are reduced as individuals discover, through experimentation, personal contact, and identification, that cooperative action is both possible and privately beneficial. Regulatory responses to environmental degradation using coercion and force, while necessary in certain contexts, cannot be expected to duplicate the success of long term, mutually beneficial exchange relationships in transforming human activity. 


\section{APPENDIX A}

The following three examples reveal the importance of knowing the relationship between $R_{c}$ and $R_{u}$ in producing the shape of three intermediate curves where:

$$
\begin{aligned}
L_{n} & =E C U_{o}-E C U_{r}+E Q U_{r} \\
E Q & =R_{c} E C \\
U_{r} & =R_{u} U_{o} \\
L_{n} & =E C U_{o}-E C R_{u} U_{o}+R_{c} E C U_{r} \\
& =E C U_{o}\left(1-R_{u}+R_{e} R_{u}\right) \\
& =L_{o}\left(1-R_{u}+R_{c} R_{u}\right)
\end{aligned}
$$

\section{CASE 1}

In the case where $R_{u}=1-\left(1-R_{e}\right)^{2}$

$$
L_{n}=L_{o}\left(1-\left(1-\left(1-R_{c}\right)^{2}\right)+R_{c}\left(1-\left(1-R_{c}\right)^{2}\right)\right)
$$

For example, where $R_{e}=5$, then $L_{n}=.625 L_{o}$

\section{CASE 2}

In the case where, $R_{u}=R_{c}=R$

$$
L_{n}=L_{0}\left(1-R+R^{2}\right)
$$

For example, where $R_{c}=.5$, then $L_{n}=.75 L_{o}$

In the case where $R_{u}=R_{c}{ }^{2}$

\section{CASE 3}

$$
L_{n}=L_{o}\left(1-R_{c}^{2}+R_{c}^{3}\right)
$$

Then where $R_{c}=.5$, then $L_{n}=.875 L_{o}$. 